\title{
SPICOL conference revisted
}

\section{By PAT CRADDOCK}

SPICOL was held the following years, in 1997 and 1998, at the university. The participants for the later SPICOL conferences were different students, but they were still acting out the elegant roles of prime ministers, foreign ministers and policy advisers. In 1997, they enjoyed their opening feast and took part in high powered discussions with their South Pacific colleagues on "Tourism in the 21 st Century".

It was a different scene for the journalism students. One journalism students with previous experience of the first SPICOL was appointed press officer. The PO handled all requests for interviews with prime ministers and other dignitaries. Students contacted her and she set up interview times. In theory it worked well, as the PO position had grown out of the recommendations of the first SPICOL. In practice the theory had problems. Journalism students who set up times for the interviews often had to wait well beyond the set time for the dignitaries to appear. Some of these officials have yet to meet the journalists for the planned interviews. Two of the journalists also failed to meet their officials at the set time. Their excuse was that they were busy doing other work. But while a prime minister may keep a journalist waiting, it is obviously unsatisfactory for a journalist to keep a prime minister twiddling fingers and getting annoyed with the media.

The radio students still found difficulty is covering the many aspects of the conference. Their "soundbites" were often incidental to the story they had written. This resulted in the listener hearing the voice of a participant, eg a Foreign Minister, but in most cases he/she was not talking about the issue related to the radio news item. The soundbite was more often than not mere decoration.

Technical quality of the sound bites was of a low standard. Many could not be used. One student was seen holding up a microphone in the middle of a group discussion. The room was large; the incidental noise was enough to dominate the sound the person speaking who was at least ten metres away from the raised microphone. For those who are not radio trained, trying to record any distance over half a metre is a handicap to good audio quality 


\section{SPICOL CONFERENCE REVISTED}

unless you have special equipment.

Post-analysis of the SPICOL event showed up one more need. Few of the conference interviewees showed an ability to talk easily in front of a microphone. This comment came from several journalism students and also the participants of the conference. It was suggested that the following year the press officer or the journalism lecturers give the prime ministers and their entourages a lesson in handling the media, in order that the politicians could look and sound presentable.

As I digested the impact of having to train young budding politicians to look and sound good in front of the media, I knew it was time to go home and be alone with my thoughts while I sipped either a coffee or cognac or perhaps both.

Horn, Andrew (1997), "Television in the Pacific", Wansolwara, Suva: USP, Fiji. Vol 2, No 2,10-11, June.

Masterton, Murray (1994), "The media of PNG and the Pacific Islands", Comparative Journalism : Study Guide, Geelong, Victoria: Deakin University.

Meadows, Michael (1997), Radio interview, USP Media Centre, Suva, Fiji, July.

Sen, Sadhana, (1997), Personal interview, USP Media Centre, Suva, Fiji, June.

- Patrick Craddock is Senior Radio Producer in Distance Education and Media Centre and Associater Lecturer Journalism, University of the South Pacific. This paper was prepared in September 1997 for a media conference in South Africa under the original title, "Students Surfing, Sinking and Swimming Inside the World Trade Organisation".

Email: Craddock_P@usp.ac.fj 